\title{
Vorbemerkungen zur Schreibweise von Orts- und Personennamen
}

„Consistency here would have ludicrous results.“

Peter Jackson ${ }^{1}$

Aufgrund der Spezifik meiner Untersuchungsregion, die lange Zeit Gegenstand von widerstreitenden nationalen Forschuxngstraditionen war, sind noch einige Worte zu der von mir gewählten Schreibweise von Orts- und Personennamen notwendig. ${ }^{2}$ Be-

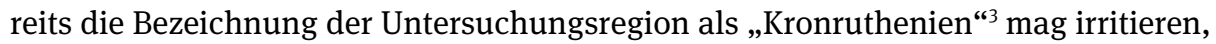
ist doch etwa der Begriff „Rotreußen“ in der deutschen Forschung deutlich verbreiteter. Allerdings sind weder sein Ursprung noch sein geographischer Umfang genau bestimmbar. ${ }^{4}$ Im Vergleich dazu umfasst der Begriff „Kronruthenien“ sehr klar die Gebiete der Rus', die an die polnische (bzw. phasenweise ungarische) Krone übergingen. Ferner vermeidet er das anachronistische „Reußen“.

Hinsichtlich einer möglichst gendergerechten Sprache habe ich mich in der vorliegenden Arbeit für das generische Femininum entschieden, wenn mit einem Kollektivbegriff Menschen verschiedenen Geschlechts und sexueller Orientierung gemeint sind. Dies bezieht sich vorrangig auf die Zeit ab dem 19. Jahrhundert. Für die Analyse der Personen im Untersuchungszeitraum lässt sich dies schwerlich anwenden, da im Spiegel der Urkunden zum überwiegenden Teil männliche Personen aufscheinen. Hier verwende ich vor allem das Maskulinum, spreche also von Empfängern, Akteuren oder Zeugen. Dennoch finden die weiblichen Akteurinnen - Königinnen, Erbinnen und Witwen - die ihnen gebührende Berücksichtigung in dieser Arbeit.

Einzelne Ortsnamen werden - sofern sie eindeutig identifizierbar waren ${ }^{5}$ - in der Form ihrer heutigen nationalstaatlichen Zugehörigkeit wiedergegeben, bei ukrainischen und belarusischen Orten in ihrer wissenschaftlichen Transliteration ${ }^{6}$. Nicht identifizierte Orte werden kursiv in der Schreibweise der jeweiligen Quelle angegeben.

\footnotetext{
1 Jackson, Mongols (2005), XXV.

2 Ich habe mich u. a. am Vorgehen von Mykhaylovskiy, European Expansion (2019), 11 orientiert.

3 „Kronruthenien“ ist die wörtliche Übertragung von „Ruś koronna“, wie er auch in jüngeren polnischen Publikationen zunehmend Verwendung findet, vgl. etwa Janeczek, Udział (2010).

4 Der Begriff taucht nicht vor dem 15. Jahrhundert auf, hat aber keinen Bezug zu den sogenannten „Czerwenischen Burgen“ des frühen Hochmittelalters, vgl. Von Werdt, Stadt (2006), 21 Anm. 101; Paszkiewicz, Origin (1954), 65 Anm. 3. Zu den „Czerwenischen Burgen“ vgl. etwa Janeczek, Boundaries (2015) sowie Wołoszyn, Towns (2017).

5 Vgl. die Vorbemerkungen zum Repertorium hinsichtlich des Vorgehens zur Identifizierung der Orte. 6 Ich orientiere mich dabei an DIN 1460, vgl. die Übersicht von Daniel Bunčić, die von der Universität Köln bereitgestellt wird: https://kups.ub.uni-koeln.de/11288/ (Zuletzt besucht: 26.09.2020).
} 
Bei der Schreibweise von Personennamen orientierte ich mich am transnational angelegten Buch von Robert Frost ${ }^{7}$ : Bei den Herrscherinnen und Herrschern habe ich mich für die Namensform in der heutigen Landessprache der jeweiligen Herrschaftsgebiete entschieden, d. h. die polnischen Könige heißen Kazimierz und Władysław während etwa die Großfürsten von Litauen Vytautas oder Žygimantas genannt werden. Allein die ungarischen Könige werden aufgrund ihrer engen Verbindung mit Mittel- und Südeuropa Ludwig und Sigismund genannt. Bei den ungarischen Königinnen nenne ich Ludwigs Mutter, Tochter des polnischen Königs Władysław Łokietek, entsprechend Ełżbieta Łokietkówna, die zweite Gemahlin Ludwigs hingegen Elisabeth von Bosnien. ${ }^{8}$

Im Hinblick auf die Akteurinnen und Akteure der Meso-Ebene werden die meisten Namensformen entsprechend der Quellenbegriffe latinisiert angegeben. Allein bei klar als ruthenisch identifizierbaren Personen wird die Namensform auf Basis der wissenschaftlichen Transliteration gebildet. Die Herkunft der Mehrzahl der Personen ist durch einen Ortszusatz bestimmbar. ${ }^{9}$ Ist dieser Ort identifizierbar, wird er mit „von“ an den Vornamen der Person angefügt. Ist dies nicht der Fall, wird auch hier die lateinische Hilfskonstruktion benutzt: Der Name wird dann gemäß der Quellenschreibweise kursiv mit einem „de“ an den Vornamen angefügt. Allein bei identifizierbaren Orten, die stark von ihrem Quellennamen abweichen, habe ich mich ebenfalls für die zweite Form entschieden, weil es sonst $\mathrm{zu}$ einer $\mathrm{zu}$ künstlichen Abweichung von der in der Forschung gängigen Schreibweise gekommen wäre. ${ }^{10}$ Eine weitere Ausnahme sind Personen, die bereits einen Nachnamen vorweisen, so etwa bei Johannes oder Petrus Kmita. Auch die Amtsbezeichnungen werden überwiegend kursiviert angegeben. Als deutsche Entsprechung für Amt des Capitaneus (meist Russie) findet sich aber auch der Terminus „Kapitan“. Hinsichtlich der verschiedenen christlichen Konfessionen benutzte ich mit aller Vorsicht die Begriffe „lateinchristlich“ für die Kirchen, die sich der päpstlichen Kurie, bzw. „orthodox“ für diejenigen, die sich einem der verschiedenen Patriarchate zuordneten.

Bei Forschungsliteratur, die auf Ukrainisch, Russisch oder Belarusisch erschienen ist, behalte ich die Angabe im kyrillischen Alphabet bei. Angesichts unterschiedlicher Transliterationen in der internationalen Forschung soll dies den Leserinnen die eigene Recherche erleichtern. Im Siglen-, sowie im Quellen- und Literaturverzeichnis werden die kyrillischen Nennungen gesondert nach denen im lateinischen Alphabet angeführt.

7 Vgl. Frost, History (2015), xx-xxi.

8 Vgl. Kapitel 2 zu den einzelnen genannten Herrscherinnen und Herrschern.

9 Vgl. dazu auch die Vorbemerkungen zum Repertorium.

10 Beispielsweise bleibt bei Benko de Żabokruki die Ortsbezeichnung kursiv stehen, da der heutige Name Kvitneve stark vom Quellenbegriff abweicht. Benko de Żabokruki ist in dieser Namensform als einer der wichtigsten Akteure in der Forschung weithin bekannt. Ein weiteres Beispiel wäre Cristinus von Ostrów, was sich auf das heutige Ostrowiec Świętokrzyski bezieht, vgl. Kurtyka, Tęczyńscy (2017), 645. 



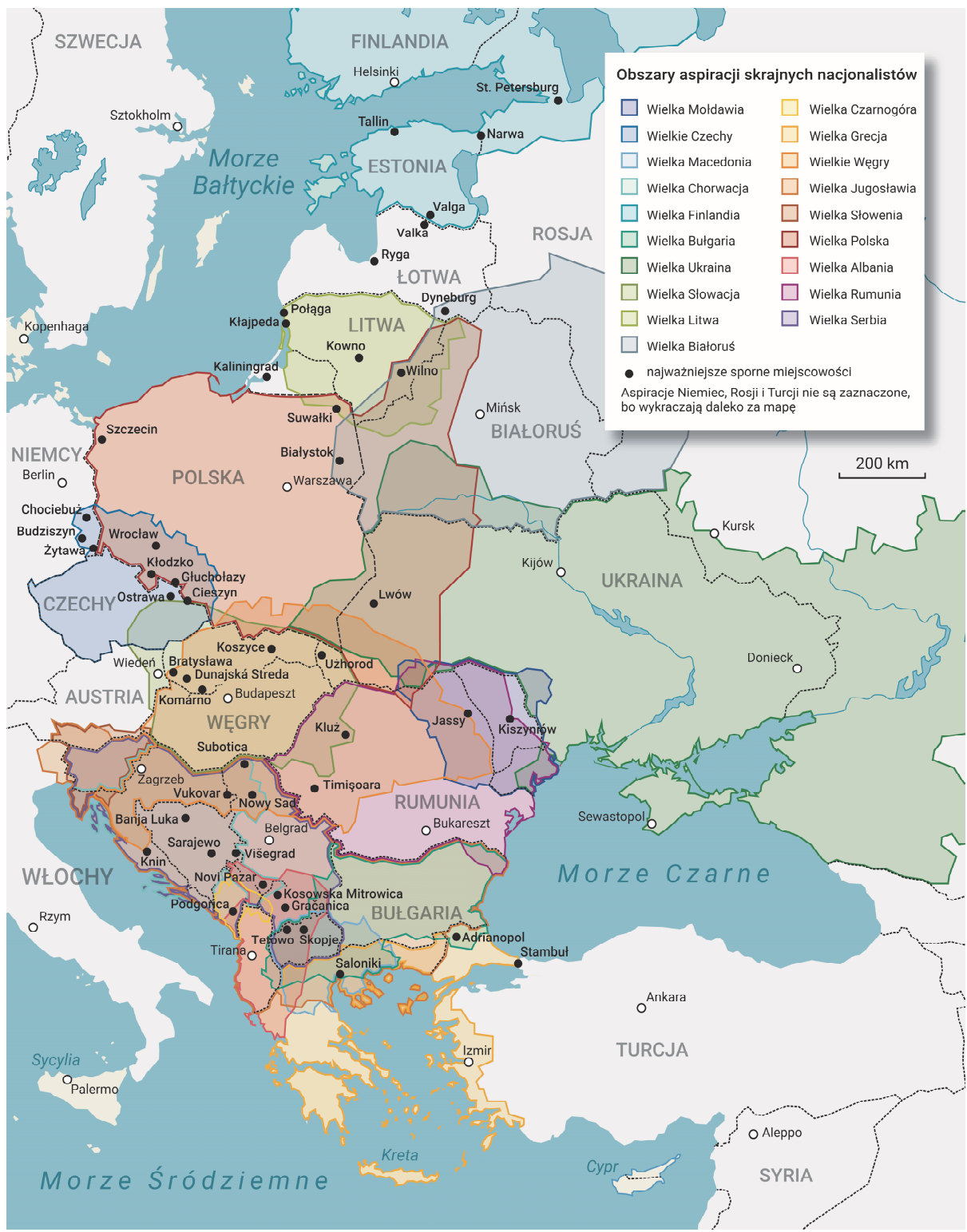

Abb. 1: Karte der Anspruchsgebiete extremer Rechter im östlichen Europa - aus: Szczerek, Międzymorze (2017), Einband. (Karte erstellt von: Wawrzyniec Święcicki). 